\title{
Comparative Study on Gas Exchange, Water Relations and Leaf Anatomy of Two Olive Cultivars Grown under Well-Irrigated and Drought Conditions
}

\author{
Konstantinos Chartzoulakis ${ }^{\mathrm{a}, *}$, Angelos Patakas ${ }^{\mathrm{b}}$ and Artemis Bosabalidis ${ }^{\mathrm{c}}$ \\ a NAGREF, Subtropical Plants and Olive Tree Institute,73100 Chania, Crete, Greece. \\ Fax: +3082193963. E-mail: agres@cha.forthnet.gr \\ ${ }^{\mathrm{b}}$ Laboratory of Viticulture, Aristotle University, P.O Box 236, 54006 Thessaloniki, Greece \\ ${ }^{c}$ Department of Botany, School of Biology, Aristotle University, 54006 Thessaloniki, Greece \\ * Author for correspondence and reprint requests \\ Z. Naturforsch. 54c, 688-692 (1999); received November 8, 1998/February 16, 1999 \\ Leaf Anatomy, Olea europea, Osmotic Adjustment, Photosynthesis, Drought Stress
}

The effect of water stress on gas exchange, water relations and leaf anatomical characteristics have been studied in two olive cultivars (Olea europea, L. cv. 'Koroneiki' and cv. 'Mastoidis'). Photosynthetic rate as well as stomatal conductance were decreased in stressed plants. Osmotic potential $(\pi)$ declined rapidly in stressed plants indicating their ability for osmoregulation. Bulk modulus of elasticity $(\varepsilon)$ was significantly higher in stressed compared to well irrigated plants. The volume fraction of intercellular spaces of the upper palisade parenchyma, the spongy parenchyma as well as the lower palisade parenchyma were significantly lower in stressed compared to well irrigated plants. On the other hand, the density of mesophyll cells in the upper palisade parenchyma, spongy parenchyma and lower palisade parenchyma increased significantly in stressed plants.

\section{Introduction}

Olive tree, native in Mediterranean basin, is usually during summer subjected to drought stress due to high temperatures, high vapour pressure deficit and limited water availability, as a result of lack of precipitation or insufficient irrigation. The importance of stomatal regulation on leaf gas exchange under drought has been recently emphasized (Chaves, 1991).

The maintenance of turgor $(\mathrm{P})$ during a change in the plant water status is supposed to preserve metabolic processes of the plants and aim in its growth and productivity (Hsiao, 1973; Morgan, 1984). Lowering of osmotic potential $(\pi)$ due to net solute accumulation as well as changes in cell wall elasticity $(\varepsilon)$ are well established ecophysiological mechanisms which contribute in turgor maintenance in plants under drought conditions (Morgan, 1984; Patakas and Noitsakis, 1997).

On the other hand, water stress can also affect leaf anatomical parameters by causing changes in the number, density of mesophyll cells and/or cellular dimensions. These result in alterations of internal leaf area being available for the $\mathrm{CO}_{2}$ absorption per unit leaf surface area and thus influence photosynthetic rate (Nobel, 1991).
In the Mediterranean region and especially in Crete, two cultivars - 'Koroneiki' and 'Mastoidis' - are widely cultivated because of their economical significance and they are both concerned as well adapted to drought conditions.

The aim of this study was to evaluate the ecophysiological mechanisms contributing in turgor maintenance in these two olive cultivars grown under water stress conditions as well as to elucidate the leaf anatomical alterations caused by drought in these cultivars.

\section{Materials and Methods}

The experiment was conducted at the Institute of Subtropical Plants and Olive Tree, Chania, Crete. Three year old own-rooted olive trees (Olea europea, P. cv. 'Koroneiki' and cv. 'Mastoidis'), were used. Twenty plants of each cultivar were grown outdoors in 501 pots, containing freely drained light soil (sandy loam). Different soil water regimes were imposed to both cultivars during the dry season (April to October). Stress cycle was induced in ten selected plants of each cultivar at the beginning of July 1995 by withholding irrigation while the other ten plants (control) continued to receive daily irrigation. Tensiometers and Buy- 
oucos blocks placed at $20 \mathrm{~cm}$ depth were used for monitoring soil water tension in stressed plants. These plants were irrigated only when soil water tension reached $-1.5 \mathrm{MPa}$, about nine days after irrigation was stopped. The experiment was repeated in 1996. No significant differences were obtained between measurements on the two years and hence the results following represent the measurements of the first year (1995).

Predawn water potential $(\psi)$ and osmotic potential $(\pi)$ were measured every day during the drought cycle using thermocouple psychrometers (Wescor HR-33). Measurements of water and osmotic potential were made on six leaf discs $(0.38$ $\mathrm{cm}^{2}$ ) per treatment obtained from the $3-4^{\text {th }}$ fully expanded leaf from the tip at 0600 a.m. Turgor potential $(\mathrm{P})$ - the positive internal pressure to the cell walls - was calculated as:

$$
P=\psi-\pi \text {. }
$$

Concomitant measurements of relative water content (RWC) were made on six leaf discs obtained from the same leaves that were used for the determination of water potential components (Patakas and Noitsakis, 1997). The bulk modulus of elasticity $\varepsilon$-an index of the elastic properties of cell walls- was calculated in both cultivars using the equation (Koide et al., 1991):

$$
\varepsilon=(\Delta P / \Delta \mathrm{RWC}) \times 100 .
$$

Osmotic potential due to net solute accumulation $\left(\pi_{\mathrm{s}}\right)$ was calculated using the equation:

$$
\pi_{\mathrm{s}}=\pi-\left[\left(\pi_{100} \times \mathrm{RWC}_{100}\right) / \mathrm{RWC}\right],
$$

where $\pi$ and RWC are the osmotic potential and the relative water content respectively at a meas- ured $\psi$ value; $\pi_{100}$ and $\mathrm{RWC}_{100}$ are the osmotic potential and relative water content at full turgor with $\left(\pi_{100} \times \mathrm{RWC}_{100}\right) / \mathrm{RWC}$ being the osmotic potential due to passive solute concentration with water loss. The values of $\pi_{100}$ were derived from the linear regression equation that was used to describe the relationship between $\pi$ and $\psi$ in each cultivar during the drought cycle (Wright et al., 1997). Similarly, the $\mathrm{RWC}_{100}$ values for each cultivar derived from the relationship between RWC and $\psi$.

Gas exchange measurements were made daily, between 9 and 10 a.m, on six leaves per treatment using a portable gas exchange system (Li-6200, LiCor Inc).

For anatomical studies pieces from 12 leaves per each treatment, taken at the end of the experiment (October 1996), were fixed for $3 \mathrm{~h}$ in 5\% glutaraldehyde buffered with 0.025 m sodium phosphate to $\mathrm{pH}$ 7.2. Samples were then washed in the respective buffer and post-fixed for $5 \mathrm{~h}$ in $1 \%$ osmium tetroxide similarly buffered. Tissue dehydration was carried out in an alcohol series followed by infiltration and final embeddent in Spur's resin. Cross as well as paradermal sections for light microscopy (1ìm thick) were obtained in a Reichert Om U2 ultramicrotome, stained with $1 \%$ toluidine blue $\mathrm{O}$ in borax, and examined with a Zeiss III photomicroscope.

\section{Results and Discussion}

Photosynthetic rate as well as stomatal conductance decreased in stressed plants of both cultivars during the drought cycle (Fig. 1). Water relations

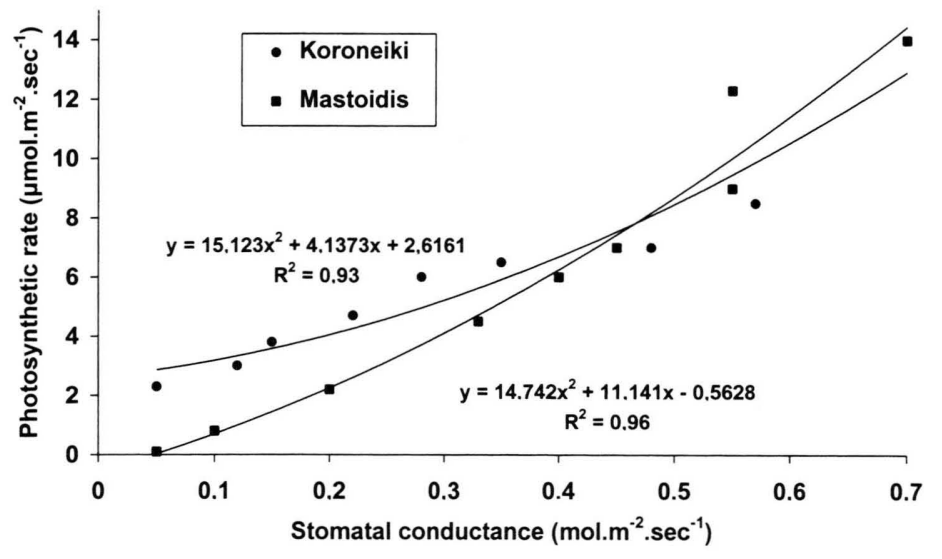

Fig. 1. Changes in photosynthetic rate in relation to stomatal conductance in the two olive cultivars during the drought cycle. 


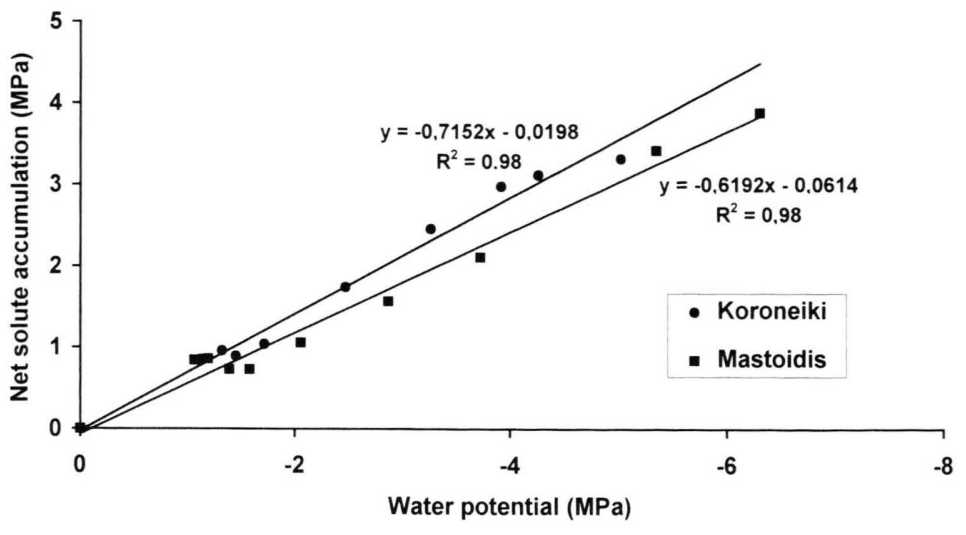

Fig. 2. Relationship between net solute accumulation and leaf water potential in the two olive cultivars during the drought cycle.

Table I. Leaf water potential parameters as well as bulk modulus of elasticity $(\varepsilon)$ in well irrigated and stressed plants of the two olive cultivars. $(n=6, \pm \mathrm{SD})$.

\begin{tabular}{lrrrr}
\hline & \multicolumn{2}{c}{ Mastoidis } & \multicolumn{2}{c}{ Koroneiki } \\
& Irrigated & \multicolumn{1}{c}{ Stressed } & Irrigated & \multicolumn{1}{c}{ Stressed } \\
\hline Water potential $(\mathrm{MPa})$ & $-0.85 \pm 0.04$ & $-5.65 \pm 0.10$ & $-0.82 \pm 0.06$ & $-5.02 \pm 0.15$ \\
Osmotic potential $(\mathrm{MPa})$ & $-1.95 \pm 0.09$ & $-6.32 \pm 0.12$ & $-1.85 \pm 0.09$ & $-5.19 \pm 0.14$ \\
$\varepsilon(\mathrm{MPa})$ & $1.40 \pm 0.23$ & $2.78 \pm 0.45$ & $1.51 \pm 0.25$ & $2.52 \pm 0.48$ \\
\hline
\end{tabular}

parameters recovered fully overnight after rewatering the plants in the afternoon, while photosynthesis and stomatal conductance showed a partial recovery (data not shown).

Water and osmotic potential decreased significantly in the stressed plants of both cultivars reaching minimum values at the end of the drought cycle (Table I). Net solute accumulation accounted for almost $63 \%$ of the changes in os- motic potential in the stressed plants of both cultivars indicating the occurrence of an active osmotic adjustment (Fig. 2). Furthermore, the value of the bulk modulus elasticity $(\varepsilon)$ also increased significantly in stressed plants compared to the well irrigated. These results indicate that both osmotic adjustment and changes in tissue elasticity contribute in turgor maintenance in olive plants under water stress conditions.

Table II. Volume fractions (\%) of the leaf histological components in the two olive cultivars under well irrigated and stressed conditions $(n=12, \pm \mathrm{SD})$.

\begin{tabular}{lrrrr}
\hline & \multicolumn{2}{c}{ Mastoidis } & \multicolumn{2}{c}{ Koroneiki } \\
& Irrigated & \multicolumn{1}{c}{ Stressed } & Irrigated & \multicolumn{1}{c}{ Stressed } \\
\hline $\begin{array}{l}\text { Volume fraction of upper } \\
\text { palisade parenchyma }\end{array}$ & $22.8 \pm 1.6$ & $23.6 \pm 0.6$ & $25.8 \pm 1.4$ & $26.5 \pm 0.8$ \\
$\begin{array}{c}\text { Volume fraction of upper } \\
\text { palisade intercellular spaces }\end{array}$ & $9.2 \pm 0.7$ & $6.3 \pm 0.4^{*}$ & $12.9 \pm 0.9$ & $8.6 \pm 0.7^{*}$ \\
$\begin{array}{c}\text { Volume fraction of the spongy } \\
\text { parenchyma }\end{array}$ & $15.4 \pm 1.5$ & $27.2 \pm 1.0^{*}$ & $19.9 \pm 1.6$ & $23.8 \pm 1.0^{*}$ \\
$\begin{array}{c}\text { Volume fraction of the spongy } \\
\text { parenchyma intercellular spaces }\end{array}$ & $22.9 \pm 1.9$ & $16.4 \pm 1.1^{*}$ & $16.0 \pm 1.9$ & $15.0 \pm 1.1^{*}$ \\
$\begin{array}{c}\text { Volume fraction of the lower } \\
\text { palisade parenchyma }\end{array}$ & $4.5 \pm 0.5$ & $6.2 \pm 0.6^{*}$ & $5.1 \pm 0.8$ & $5.6 \pm 0.4^{*}$ \\
$\begin{array}{c}\text { Volume fraction of the lower } \\
\text { palisade intercellular spaces }\end{array}$ & $4.6 \pm 0.7$ & $3.2 \pm 0.5^{*}$ & $4.5 \pm 0.5$ & $3.7 \pm 0.4^{*}$ \\
\hline
\end{tabular}

* Statistically significant from the control, $\mathrm{P}<0.05$. 
Leaves of both stressed olive cultivars appeared in cross sections thinner than the well irrigated leaves (Fig. 3). The volume fraction of intercellular spaces of the upper palisade parenchyma, the spongy parenchyma as well as the lower palisade parenchyma were significantly lower in stressed compared to well irrigated pants (Table II). Furthermore the total volume of cells in the spongy and in the lower palisade parenchyma increased significantly in stressed plants. Comparative observations of the paradermal sections at the levels of upper palisade parenchyma, spongy
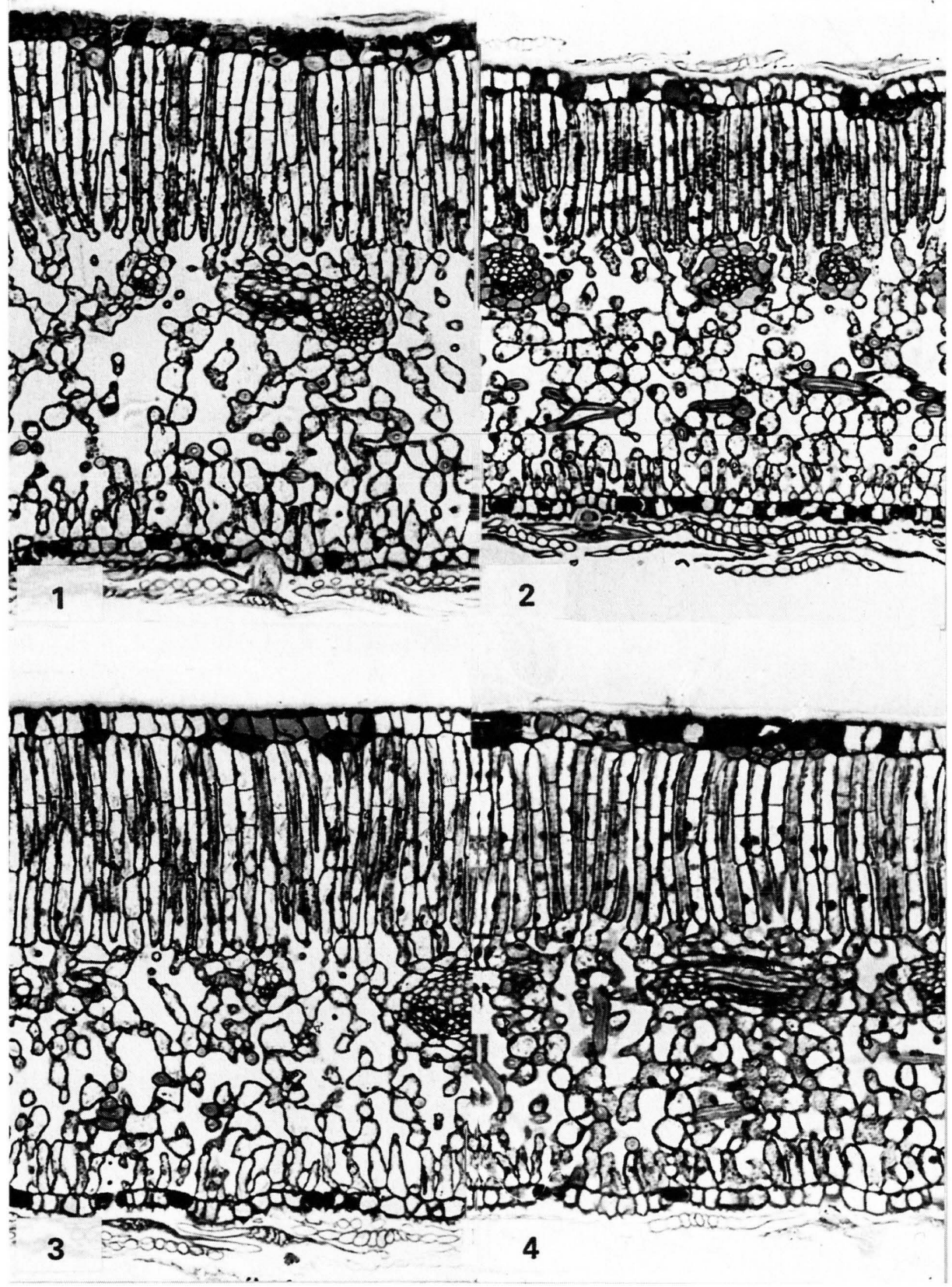

Fig 3. Comparative leaf anatomy in blade cross sections of 'Mastoidis' $(1,2)$ and 'Koroneiki' (3, 4) leaves grown under well irrigated $(1,3)$ and water stress conditions (2, 4). (X200). 
Table III. Density $\left(\mathrm{No} / \mathrm{mm}^{2}\right)$ of mesophyll cells in paradermal sections of the two olive cultivars grown under well irrigated and water stressed conditions $(n=12, \pm \mathrm{SD})$.

\begin{tabular}{lllll}
\hline & \multicolumn{2}{c}{ Mastoidis } & \multicolumn{2}{c}{ Koroneiki } \\
& Irrigated & Stressed & Irrigated & Stressed \\
\hline Upper palisade parenchyma & $6657 \pm 566$ & $8761 \pm 707^{*}$ & $7075 \pm 586$ & $9049 \pm 903$ \\
Spongy parenchyma & $1081 \pm 122$ & $1239 \pm 104 *$ & $1268 \pm 135$ & $1398 \pm 211^{*}$ \\
Lower palisade parenchyma & $3646 \pm 464$ & $5231 \pm 381 *$ & $3761 \pm 485$ & $5476 \pm 506^{*}$ \\
\hline
\end{tabular}

* Statistically significant from the control, $\mathrm{P}<0.05$.

parenchyma and lower parenchyma between irrigated and stressed plants showed that in the latter the density of cells $\left(\mathrm{No} / \mathrm{mm}^{2}\right)$ in all of the leaf histological components significantly increased in both cultivars (Table III). These changes on anatomical characteristics would lead to an increase in the mesophyll surface area per unit leaf area (Ames/A) which in turn could facilitates $\mathrm{CO}_{2}$ uptake and thus maintain photosynthetic rate although stomatal conductance presented low values under drought conditions. On the other hand, the decrease in volume fraction of intercellular spaces occurred under water stress conditions is expected to decrease the diffusion component of

Chaves M. M. (1991), Effect of water deficits on carbon assimilation. J. Exp. Bot. 42, 1-16.

Hsiao T. C. (1973), Plant responses to water stress. Annu. Rev. Plant Physiol. 24, 519-570.

Koide R. T., Robichaux R. H., Morse S. R. and Smith C. M. (1991), Plant water status, hydraulic resistance and capacitance. In: Physiological Ecology (R. W. Pearcy, J. Ehleringer, H. A. Mooney and P. W. Runder, eds.). Chapman and Hall, London - New York, pp. 161-187.

Morgan J. M. (1984), Osmoregulation and water stress in higher plants. Annu. Rev. Plant Physiol. 35, 299-319.

Nobel P. S. (1991), Leaves and fluxes. In: Physicochemical and Environmental Plant Physiology (P. S. Nobel,
$\mathrm{CO}_{2}$ conductance through the intercellular spaces from the substomatal cavity to the outer surface of the mesophyll cells. It seems that this component of the total internal conductance of $\mathrm{CO}_{2}$ (Syvertsen et al., 1995) might be considered of less importance in olive trees. A more detailed studies as well as an estimation of the components of the total internal $\mathrm{CO}_{2}$ conductance in olive leaves are needed.

\section{Acknowledgments}

The authors wish to thank Prof. B. Noitsakis for his helpful comments and advice and Mr. G. Papadakis for technical assistance.

ed.), Chapter 8. Academic Press, San Diego, CA, pp. $393-472$.

Patakas A. and Noitsakis B. (1997), Cell wall elasticity as a mechanism to maintain favorable water relations during leaf ontogeny in grapevines. Am. J. Enol. Vitic. 48, $352-358$.

Syvertsen J. R., Lloyd J., McConchie C., Kriedemann P. E. and Farquhar G. D. (1995), On the relationship between leaf anatomy and $\mathrm{CO}_{2}$ diffusion through the mesophyll of hypostomatous leaves. Plant Cell Environ. 18, 149-157.

Wright P. R., Morgan J. M. and Jessop, R. S. (1997), Turgor maintenance in Brassica napus and $B$. juncea under field conditions. Ann. Bot. 80, 313-319. 